\title{
Experimental Assessment of a Variable Orifice Flowmeter for Respiratory Monitoring
}

\author{
Giuseppe Tardi, Carlo Massaroni, Paola Saccomandi, and Emiliano Schena
}

Università Campus Bio-Medico di Roma, Via Alvaro del Portillo 21, 00128 Rome, Italy

Correspondence should be addressed to Emiliano Schena; e.schena@unicampus.it

Received 22 March 2015; Accepted 9 July 2015

Academic Editor: Kourosh Kalantar-Zadeh

Copyright (C) 2015 Giuseppe Tardi et al. This is an open access article distributed under the Creative Commons Attribution License, which permits unrestricted use, distribution, and reproduction in any medium, provided the original work is properly cited.

\begin{abstract}
Accurate measurement of gas exchanges is essential in mechanical ventilation and in respiratory monitoring. Among the large number of commercial flowmeters, only few kinds of sensors are used in these fields. Among them, variable orifice meters (VOMs) show some valuable characteristics, such as linearity, good dynamic response, and low cost. This paper presents the characterization of a commercial VOM intended for application in respiratory monitoring. Firstly, two nominally identical VOMs were calibrated within $\pm 10 \mathrm{~L} \cdot \mathrm{min}^{-1}$, to assess their metrological properties. Furthermore, experiments were performed by humidifying the air, to evaluate the influence of vapor condensation on sensor's performances. The condensation influence was investigated during two long lasting trials (i.e., 4 hours) by delivering $4 \mathrm{~L} \cdot \mathrm{min}^{-1}$ and $8 \mathrm{~L} \cdot \mathrm{min}^{-1}$. Data show that the two VOMs' responses are linear and their response is comparable (sensitivity difference of $1.4 \%$, RMSE of $1.50 \mathrm{~Pa}$ ); their discrimination threshold is $<0.5 \mathrm{~L} \cdot \mathrm{min}^{-1}$, and the settling time is about $66 \mathrm{~ms}$. The condensation within the VOM causes a negligible change in sensor sensitivity and a very slight deterioration of precision. The good static and dynamic properties and the low influence of condensation on sensor's response make this VOM suitable for applications in respiratory function monitoring.
\end{abstract}

\section{Introduction}

During artificial ventilation and function respiratory monitoring the use of flowmeters is required to perform an accurate and continuous monitoring of gas exchange. Their output is used to estimate minute volume and tidal volume; therefore their accuracy is crucial to perform a correct diagnosis and to avoid common side effects related to uncorrected mechanical ventilation [1]. Moreover, flowmeters play a crucial role in the noninvasive assessment of metabolic gas exchange of mechanically ventilated patients by indirect calorimetry [2] and in noninvasive techniques for cardiac output monitoring $[3,4]$.

In all these applications, flowmeters have to accurately monitor the patients breathing or the flow pattern delivered by mechanical ventilators. Hence, they have to fulfill strict requirements in terms of both dynamic and static metrological properties. These sensors are often used to monitor patients during long lasting ventilation; therefore they have to be able to reject both the influence of gas composition and the influence of vapor condensation [5]. This issue is crucial because (i) the gas during mechanical ventilation can experience large changes in its composition, (ii) the gas expired by patients has high relative humidity content that can result in vapor condensation, and (iii) during invasive mechanical ventilation the inspiratory gases are humidified by devices placed within the inspiratory limb of the breathing circuit, between the ventilator and the patients.

Among the large number of commercial flowmeters, differential pressure flowmeters are the most commonly used in industrial processes (in particular square edged concentric orifice meters [6]) and are widely used in mechanical ventilation and in respiratory monitoring. Their working principle is based on an orifice plate placed within the pipe in which the gas flows. The presence of the restriction causes a pressure drop across the orifice plate, according to Bernoulli's law. Although fixed orifice meters have several advantages (e.g., they are simple to manufacture, robust, and accurate and has good dynamic properties), their use in mechanical ventilation and in respiratory monitoring is limited by their nonlinear response [7]. Several patents and studies have been focused on the design of orifice flowmeters with novel 
geometrical features of the orifice (e.g., fractal shaped [8] and slotted orifice [9]), but the only solution allowing overcoming the concerns related to their nonlinearity is represented by the design of variable orifice meters (VOMs). Patents based on different configurations (e.g., flap made of flexible sheet materials like plastic or stainless steel) have been proposed [10-12]. In these transducers the flap, cut in the middle and placed into the gas stream, creates a passage area that enlarges with the flowrate increase. The consequence is that the resistance of the orifice is almost constant with the flowrate; hence the calibration curve is linear and the range of measurement is wider than fixed orifice meters [13].

Other two solutions allow obtaining a linear resistance flowmeter. These flowmeters, called pneumotachographs, are based on a resistance which consists of a number of parallel capillary tubes or of a fine wire mesh, proposed by Fleisch and Lilly, respectively $[14,15]$. Their working principle is underpinned by Hagen-Poiseuille's law; therefore the relationship between the pressure drop across the resistance and the flowrate is linear. Although these sensors are robust and have good metrological properties, their main drawback is related to the risk of vapor condensation within their resistance, which causes high measurement error [16]. In order to overcome this concern, a more complex configuration based on the heating of the capillary or of the wire mesh has been proposed.

VOMs may minimize this concern thanks to the configuration based on a single restriction.

They are used on several commercial mechanical ventilators (e.g., the ventilators Hamilton-C1, Hamilton-C2, Hamilton-C3, Hamilton-T1, Hamilton-S1, Hamilton-G5, and GALILEO by Hamilton Medical and the ventilators Bird 8400ST and Vela C by CareFusion). Despite the large use of VOMs in the field of mechanical ventilation and respiratory monitoring, scientific literature does not present studies focusing on their metrological characterization and on the influence of vapor condensation on their response, at least to our knowledge.

The aim of this work is threefold: (i) to perform the static calibration of a commercial available VOM intended for breathing monitoring. The sensitivity, the discrimination threshold, and the characteristic of bidirectionality of this sensor are investigated. Moreover, the calibration curve of two nominally identical sensors is compared to analyze their reproducibility; also the paper will (ii) experimentally assess the step response of the VOM and (iii) investigate the influence of vapor condensation on the VOM's response.

\section{Sensors Description: Design and Theoretical Background}

Orifice meters consist of an orifice plate placed in line a pipeline where gas flows. The gas which flows through the restriction created by the orifice generates a pressure drop $(\Delta P)$ between the upstream and downstream sides of the plate. The sensor's output (i.e., $\Delta P$ ) is usually measured by a differential pressure sensor connected to two pressure static taps placed upstream and downstream the plate [17].
The input-output relationship of these sensors is obtained by considering Bernoulli's equation valid:

$$
\frac{1}{2} \cdot \rho \cdot v^{2}+\rho \cdot g \cdot h+p=\text { cost }
$$

where $v$ is the gas flow velocity, $p$ the pressure, $h$ the height respect on a reference line, $g$ the gravity acceleration, and $\rho$ the fluid density. Equation (1) is valid under the simplifying hypotheses of one-dimensional flows and incompressible, nonviscous, and isothermal fluid conditions.

The $\Delta P$ generated between upstream and downstream sections of the flow obstruction, according to Bernoulli's equation, allows the estimation of the volumetric flow rate by

$$
\phi=\frac{A_{2}}{\sqrt{1-\left(A_{2} / A_{1}\right)^{2}}} \cdot \sqrt{\frac{2 \cdot \Delta P}{\rho}},
$$

where $\phi$ is the volumetric flow rate, $A_{1}$ is the inlet area of the flowmeter, and $A_{2}$ is the passage area of flow obstruction.

The input-output relationship of the orifice meter can be easily obtained by (2), and it is a root square function $\left(\Delta P \alpha \phi^{2}\right)$. The nonlinearity of the response is one of the most important limitations of these kinds of sensors, and it is overcome by the development of VOMs.

The VOM tested in this work is the "SpiroQuant P" flow sensor produced by EnviteC (Honeywell), Figures 1(a)-1(e).

It consists of a flap placed inline a pipeline where gas flows. The gas flowing through the restriction constituted by the flap generates $\Delta P$ between upstream and downstream sections of the blades, representing the output of the sensor. The symmetrical geometry of the variable orifice meter allows measuring bidirectional flow rate.

The flap, cut in the middle and placed into the gas stream, creates an opening which widens with the $\phi$ increase: the bigger the flow, the bigger the passage area of obstruction in which the fluid flows and vice versa (Figures 1(a)-1(d)). The increase of $A_{2}$ with $\phi$ entails a linearization of the inputoutput relationship reported in (2).

\section{Experimental Setup and Results}

The experimental assessment of the above-mentioned VOM has been carried out with a threefold aim: (i) to obtain the calibration curve of two nominally identical flowmeters and to investigate their metrological static properties, (ii) to assess the settling time during dynamic tests, and (iii) to investigate the influence of humidity on the flowmeter output.

3.1. Static Calibration. The static calibration of two nominally identical variable orifice meters was carried out to evaluate the sensors' sensitivity, the symmetry of their response, and the sensors reproducibility.

The VOM (Figure 2(a)) was connected through a pipe to an airflow controller (F-201C-FBC-22-V by Bronkhorst High-Tech, Figure 2(b)). A differential pressure sensor (163PC01D75 by Honeywell, range of measurement $\pm 623 \mathrm{~Pa}$, accuracy $\pm 0.15 \%$ of full scale output, Figure $2(\mathrm{e})$ ) was 

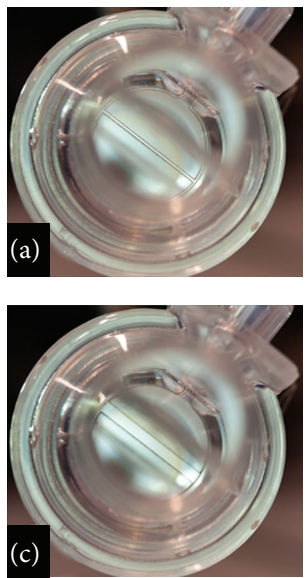
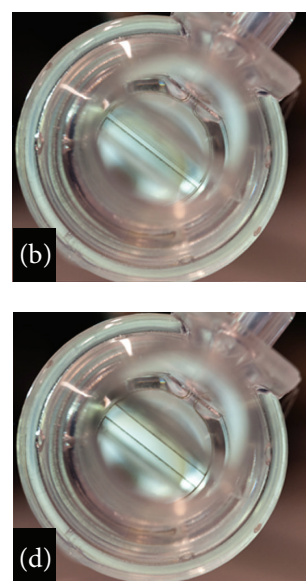

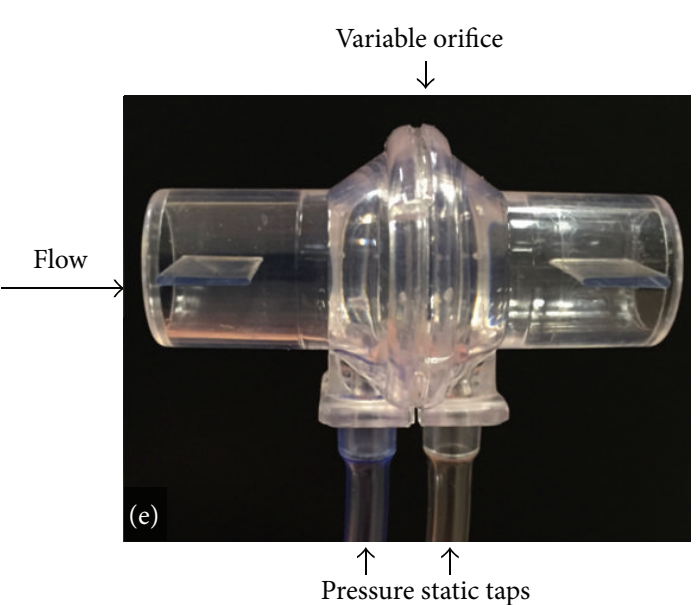

FIGURE 1: (a-d) Restriction area of the variable orifice meter: from (a) to (d) the increment of the restriction area with volumetric flowrate is shown. (e) Picture of the variable orifice meter and key components.

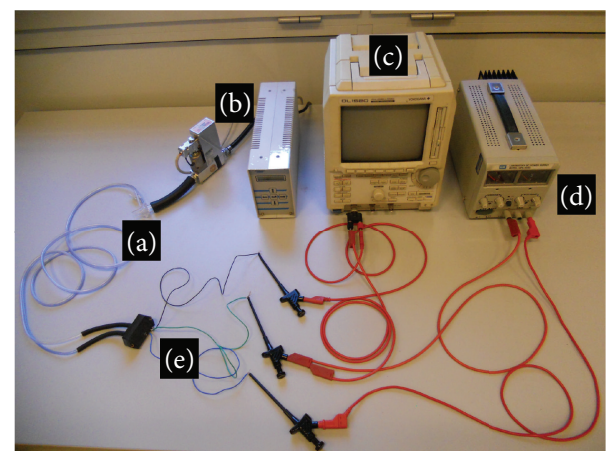

FIGURE 2: Experimental setup used to perform static calibration: (a) variable orifice meter, (b) air flow controller, (c) digital oscilloscope, (d) DC Power Supply, and (e) differential pressure sensor.

connected to the two pressure static taps, to measure the $\Delta P$ across the variable orifice. The pressure sensor was supplied by a constant voltage of $5.00 \pm 0.01 \mathrm{~V}$ by a DC Power Supply (GPS-3030, GW Instek, Figure 2(d)). The voltage output of the pressure sensor was displayed on the digital oscilloscope (DL1520 by Yokogawa, Figure 2(c)).

Two nominally identical VOMs (SpiroQuant $\mathrm{P}$ by EnviteC, Honeywell) were calibrated using the setup shown in Figure 2.

Six sets of experiments were performed on each flowmeter, by delivering constant and dry airflows ranging from $-10 \mathrm{~L} \cdot \mathrm{min}^{-1}$ to $+10 \mathrm{~L} \cdot \mathrm{min}^{-1}$ in step of $0.5 \mathrm{~L} \cdot \mathrm{min}^{-1}$. Every 5 minutes gas temperature at the flowmeter output section was monitored by a type $\mathrm{K}$ thermocouple. Gas temperature ranged in $26.0 \pm 2.0^{\circ} \mathrm{C}$ during the whole set of experiments.

The input-output relationship (i.e., $\Delta P$ versus $\phi$ ) for the two VOMs is shown in Figures 3(a) and 3(b). All the results are reported as mean \pm uncertainty; the uncertainty was calculated considering a Student reference distribution with 5 degrees of freedom and a level of confidence of 95\% (as recommended in [18]). The relationship between $\Delta P$ and $\phi$ was investigated by using a linear regression analysis. The sensors' sensitivity was estimated as the slope of the best fitting line (i.e., $\Delta P=5.306 \cdot \phi$ and $\Delta P=5.232 \cdot \phi$ for the two tested VOMs ). For each calibration curve the coefficient of determination $R^{2}$ was calculated.

Figure 3 shows that the sensors' calibration curve is well described by a linear model. The good linear fitting is confirmed by the high value of $R^{2}$ ( 0.99 for both sensors). As a consequence, the sensitivity should be considered constant in the whole range of calibration (i.e., $\pm 10 \mathrm{~L} \cdot \mathrm{min}^{-1}$ ) and equal to $5.306 \mathrm{~Pa} / \mathrm{L} \cdot \mathrm{min}^{-1}$ and $5.232 \mathrm{~Pa} / \mathrm{L} \cdot \mathrm{min}^{-1}$ for the two VOMs.

Moreover, the sensor's linearity is kept within a wider range of measurement. In fact, in order to investigate this feature we carried out trials by delivering airflow ranging from $-20 \mathrm{~L} \cdot \mathrm{min}^{-1}$ up to $+20 \mathrm{~L} \cdot \mathrm{min}^{-1}$, in step of $2 \mathrm{~L} \cdot \mathrm{min}^{-1}$; the good linear fitting was confirmed by the high value of $R^{2}$ (i.e., 0.99 ) obtained by fitting the data with a linear model.

The good reproducibility between the two sensors is witnessed by both the low difference between their sensitivities $(<1.4 \%)$ and the low value of the root mean squared error (i.e., $1.50 \mathrm{~Pa})$, which was calculated as

$$
\mathrm{RMSE}=\sqrt{\sum_{i=1}^{M} \frac{\left(\Delta P_{1}(i)-\Delta P_{2}(i)\right)^{2}}{M}},
$$

where $\Delta P_{1}(i)$ is the pressure drop for $i$ th flowrate experienced by the first sensor under test and $\Delta P_{2}(i)$ is the pressure drop for $i$ th flowrate experienced by the second sensor under test. $M$ is the number of flow rate used to calibrate the sensor (in our case $M=40$ ).

Moreover, in order to analyze the performance of the sensor in terms of bidirectionality, the gas flow was delivered in the two opposite directions to simulate inspiratory and expiratory flows. The bidirectionality was quantitatively assessed by the use of the following index of asymmetry $(S)$, proposed in [19]: 


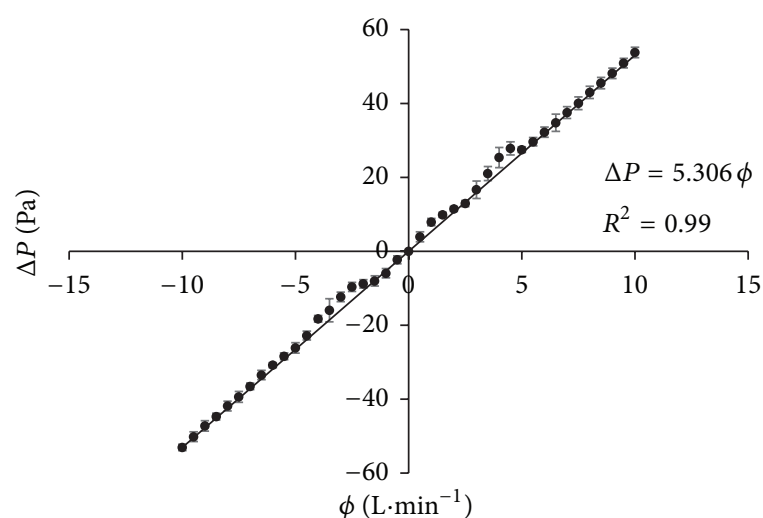

(a)

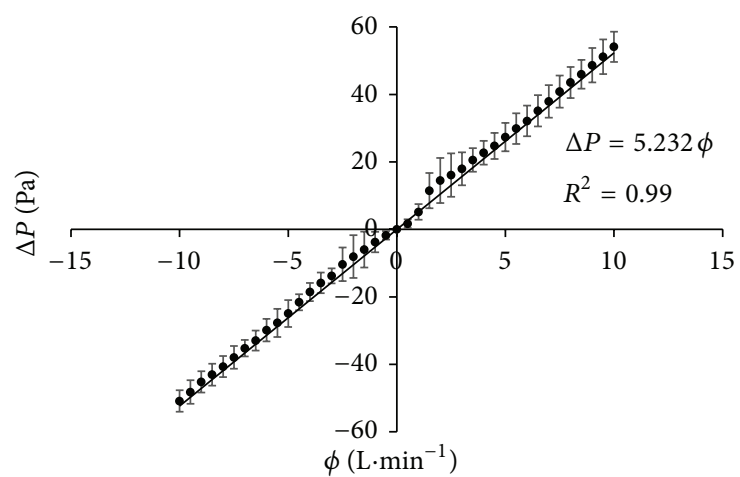

(b)

FIGURE 3: (a) and (b) Experimental data (dots) and best fitting line (continuous lines) of the two tested VOMs. The equation of the calibration curve for each sensor and the $R^{2}$ value are also reported.

$S$

$$
=\sum_{i=1}^{N} \frac{\left|\left(\left|\Delta P^{\exp }(i)\right|-\left|\Delta P^{\text {insp }}(i)\right|\right) /\left(\left|\Delta P^{\exp }(i)\right|+\left|\Delta P^{\text {insp }}(i)\right|\right)\right|}{N},
$$

where $\Delta P^{\exp }(i)$ is the pressure drop for the $i$ th flowrate value delivered in the direction of expiration and $\Delta P^{\text {insp }}(i)$ is the pressure drop for the $i$ th flowrate value blowing in the opposite direction; $N$ is the number of flowrate values used to calibrate the sensor for each direction (in our case $N=20$ ). The asymmetry index, $S$, ranges from 0 to 1 by definition: the lower its value is, the better the symmetry of sensor response is. The $S$ values were 0.14 and 0.18 for the two sensors under test.

3.2. Step Response. The dynamic response of the flowmeter was investigated by a dedicated setup.

The VOM was connected to an on/off valve (Series 8212/2NC, Matrix) with a very short switching time (i.e., $0.45 \mathrm{~ms}$ for opening and $0.19 \mathrm{~ms}$ ) already employed in previous studies $[16,19,20]$. Flowrate steps were delivered by connecting the valve to a pressurized source and quickly opening or closing the valve's orifice. The valve was controlled by a function generator (AFG313 by Sony Tektronix). Pressure drop across the orifice was transduced into a voltage by a differential pressure sensor (163PC01D75 by Honeywell, range of measurement $\pm 623 \mathrm{~Pa}$, accuracy $\pm 0.15 \%$ of full scale output). The valve and the pressure sensor were supplied by a DC Power Supply (IPS2302A by ISO-TECH). A data acquisition board (DAQ NI USB-6009 by National Instruments) connected to a Host PC recorded the voltage output of the pressure sensor. A custom made LabVIEW VI was implemented to record signals from DAQ at $1 \mathrm{kHz}$ sampling frequency. All recorded data were postprocessed in MATLAB environment.

The step response of the flowmeter under test is determined by two contributions: the contribution related to the VOM, which transduced $\phi$ into $\Delta P$, and the contribution related to the pressure sensor, which transduces $\Delta P$ into a voltage output signal.

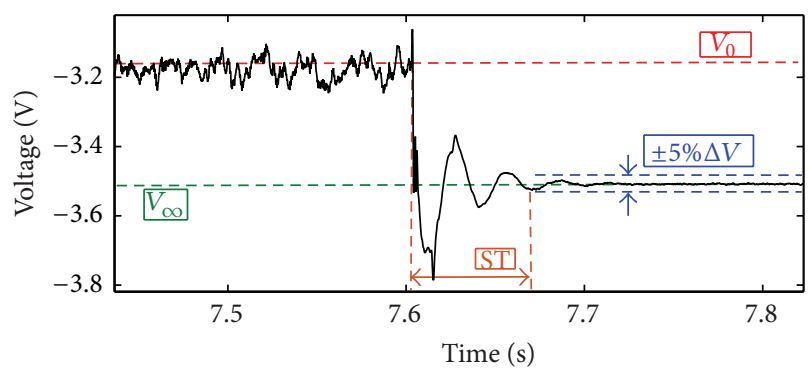

FIGURE 4: Step response of the flowmeter: trend of the pressure sensor output when a flowrate step is delivered; the estimation of the settling time is also shown.

Sensor dynamic response showed oscillations around the steady state (Figure 4). The settling time (ST), defined as the time required for the process output to reach and remain inside a band whose width is equal to $\pm 5 \%$ of the total change, was evaluated (see Figure 4).

The voltage total change $\Delta V$ was calculated as

$$
\Delta V=V_{\infty}-V_{0}
$$

where $V_{0}$ and $V_{\infty}$ are the voltage output of the pressure sensor at the step instant and at the steady state, respectively. Experiments to assess the step response of the sensor were repeated seven times (Table 1 ). The ST value calculated as mean \pm uncertainty was $66 \pm 5 \mathrm{~ms}$.

3.3. Influence of Condensation on Sensor Output. Gas flow rate with high content of water vapor $(100 \%$ of relative humidity) was delivered to investigate the influence of the humidity on VOM response. This issue is relevant in the fields of artificial ventilation and respiratory monitoring. In mechanical ventilation the airflow delivered to the patient is humidified by specific devices (e.g., heated wire humidifiers). At the output of the humidifier, airflow has high relative humidity (in many cases it is saturated) [21, 22]; also the air expired by the patients has high relative humidity and 
TABLE 1: Settling time of the sensor estimated during the seven trials.

\begin{tabular}{lcc}
\hline $\begin{array}{l}\text { Trial } \\
\#\end{array}$ & $\begin{array}{c}\text { ST } \\
{[\mathrm{ms}]}\end{array}$ & $\begin{array}{c}\text { ST } \\
{[\mathrm{ms}]} \\
\text { mean } \pm \\
\text { uncertainty }\end{array}$ \\
\hline 1 & 68.3 & \\
2 & 69.5 & \\
3 & 69.9 & $66 \pm 5$ \\
4 & 71.3 & \\
5 & 58.3 & \\
6 & 58.6 & \\
7 & 68.6 & \\
\hline
\end{tabular}

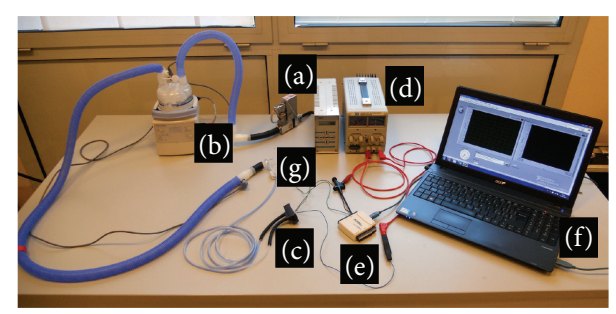

FIGURE 5: Setup used in condensation influence assessment: (a) air flow controller, (b) heated wire humidifier, (c) differential pressure sensor, (d) DC Power Supply, (e) DAQ, (f) Host PC, and (g) variable orifice meter.

in many cases it is saturated. Hence it is very important to know the influence of water vapor condensation on the performances of the flowmeter in long lasting ventilation. The condensation of water vapor within the restriction of the VOM may entail a measurement error caused by an unpredictable change in the pneumatic resistance. This phenomenon causes significant measurement error when Fleisch pneumotachographs are employed [23]. Therefore, changes of VOM response and its precision during long lasting trial were experimentally assessed. Figure 5 shows the experimental setup employed to investigate the influence of relative humidity on sensor output.

An air flow controller (F-201C-FBC-22-V by Bronkhorst High-Tech, Figure 5(a)) is connected to heated wire humidifier (MR850 by Fisher \& Paykel Healthcare, Figure 5(b)) through a limb of a breathing circuit. A second limb of breathing circuit connects the humidifier to the VOM (Figure 5(g)). The VOM's output is monitored by a differential pressure sensor (163PC01D75 by Honeywell, range of measurement $\pm 623 \mathrm{~Pa}$, accuracy $\pm 0.15 \%$ of full scale output, Figure $5(\mathrm{c})$ ) supplied by a DC Power Supply (GPS-3030, GW Instek, Figure $5(\mathrm{~d}))$. The output voltage of the pressure sensor is recorded by a data acquisition board (DAQ NI USB-6009 by National Instruments, Figure 5(e)) connected to a Host PC (Figure 5(f)). The humidifier is set to obtain the following gas thermohygrometric conditions: gas temperature of $40 \pm 1^{\circ} \mathrm{C}$ and saturation.

Long lasting experiments (i.e., 4 hours) were carried out by delivering two constant volumetric flowrates (i.e., $8 \mathrm{~L} \cdot \mathrm{min}^{-1}$ and $\left.4 \mathrm{~L} \cdot \mathrm{min}^{-1}\right)$. During each trial, the output of the pressure sensor was acquired with a sample frequency of $10 \mathrm{~Hz}$ and VOM output was calculated (Figure 6(a)). In order to investigate if the condensation causes a change in sensor's sensitivity, the four hours of trial was divided in 24 intervals (each interval lasts 10 minutes) and the mean value of the sensor's output was calculated for each interval (Figures 6(b) and $6(d)$ ). Furthermore, in order to analyze the condensation influence on the sensor's precision, the standard deviation of the sensor response was calculated for each interval (Figures 6(c) and 6(e)).

During long lasting trials performed at the two flowrates, vapor condensates within the sensor (Figure 6(f)), but the sensor sensitivity did not experience significant changes: the mean value of the sensor response is almost constant for the 24 intervals, as shown in Figures 6(b) and 6(d). The standard deviation showed a slight increase during the time (Figures 6(c) and 6(e)); for instance, the trials performed at $4 \mathrm{~L} \cdot \mathrm{min}^{-1}$ show a standard deviation of $0.66 \mathrm{~Pa}$ at the first interval (first 10 minutes of trials) and $0.69 \mathrm{~Pa}$ at the last interval (last 10 minutes of experiments). This indicates a slight deterioration of precision, but it must be noted that considering the calibration curve of the sensor (Figure 3 ) a standard deviation increase of $0.03 \mathrm{~Pa}$ corresponds to a variation of $6 \mathrm{~mL} \cdot \mathrm{min}^{-1}$ that can be considered acceptable for application in mechanical ventilation and in breathing monitoring.

Summing up, results demonstrated that the formation of condensation causes a negligible change in sensor sensitivity; the precision of the sensor experiences a slight deterioration.

\section{Discussions and Conclusions}

Mechanical ventilation and breathing monitoring are very important practice to mechanically assist patients or to perform essential diagnoses. During both artificial ventilation and function respiratory monitoring the use of flowmeters is required to perform an accurate and continuous monitoring of gas exchange. Their output is used to estimate minute volume and tidal volume; therefore their accuracy is crucial to perform a correct diagnosis and to avoid common side effects related to uncorrected ventilation [24]. By flowmeters it is possible to monitor the volumes of gases exchange by the patients.

Since strict criteria must be fulfilled (i.e., high sensitivity, good accuracy, bidirectionality, low pneumatic resistance, low volumes added to breathing circuit, short response, and large range of flat frequency response) only few kinds of flowmeters are used in these fields. The most employed flowmeters are hot wire anemometers, fixed and variable orifice meters, Fleisch pneumotachographs, and ultrasonic flowmeters [7].

Several studies focus on the performances of hot wire anemometers, fixed orifice meters, Fleisch pneumotachographs, and ultrasonic flowmeters and on their application on respiratory monitoring field [16, 25-28].

Although the first patent on VOM dates back to the 1970 s and several mechanical ventilators are equipped with this 


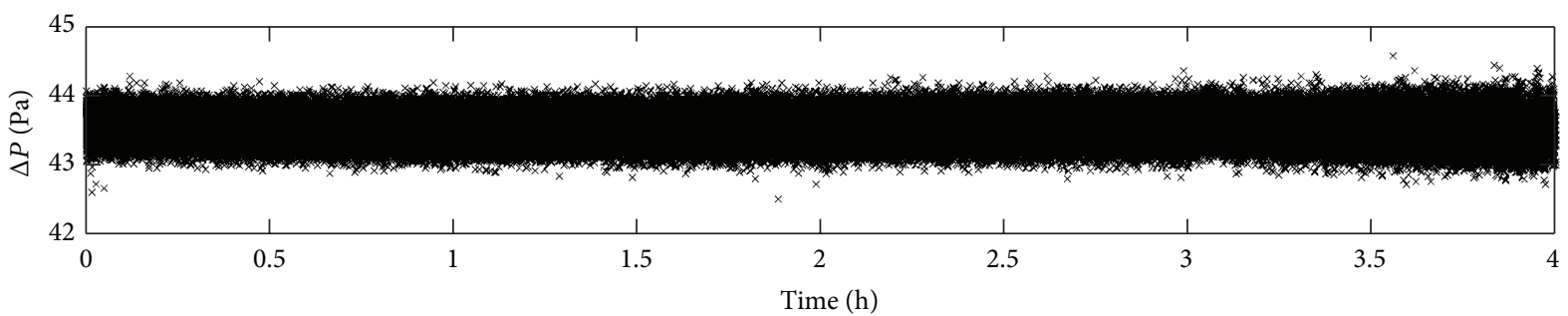

(a)

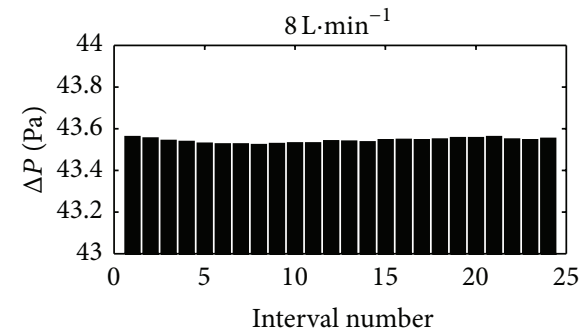

(b)

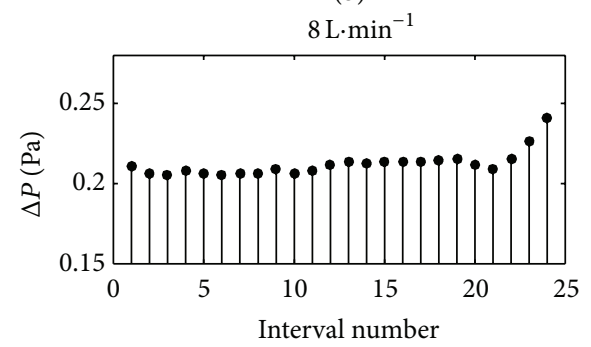

(c)

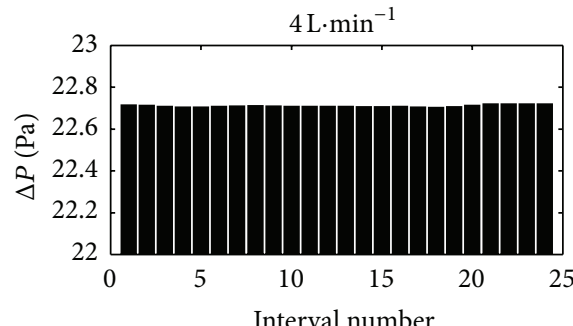

(d)

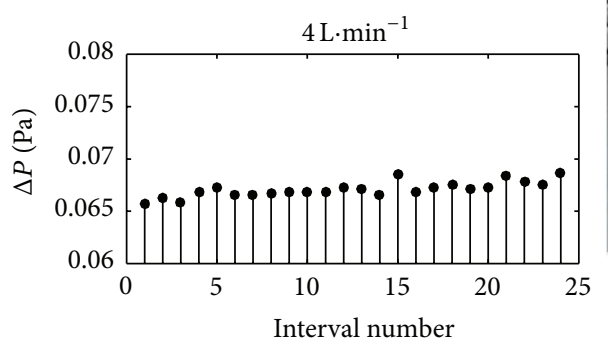

(e)

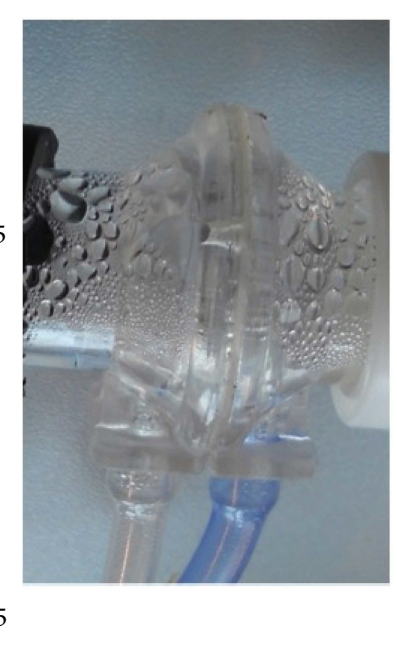

(f)

Figure 6: (a) Sensor output during 4 hours of trial at $8 \mathrm{~L} \cdot \mathrm{min}^{-1}$; (b) mean values of sensor output for each interval at $8 \mathrm{~L} \cdot \mathrm{min}^{-1}$; (c) standard deviation of sensor output for each interval at $8 \mathrm{~L} \cdot \mathrm{min}^{-1} ;(\mathrm{d})$ mean values of sensor output for each interval at $4 \mathrm{~L} \cdot \mathrm{min}^{-1} ;(\mathrm{e}) \mathrm{standard} \mathrm{deviation}$ of sensor output for each interval at $4 \mathrm{~L} \cdot \mathrm{min}^{-1}$; (f) picture of the sensor at the end of the 4-hour trial. The formation of condensation within the sensor is evident.

kind of sensor, studies regarding its metrological properties and the problem of water condensation are lacking.

The present work focuses on the static and dynamic characterization and also on the investigation of condensation influence on the output of a commercial VOM.

Experiments show that the response of this sensor is linear; hence it has a constant sensitivity and it shows excellent bidirectionality in a wide range of flowrates $\left( \pm 10 \mathrm{~L} \cdot \mathrm{min}^{-1}\right)$; by comparing the performances of two nominally identical sensors, their response shows good reproducibility (the difference between their sensitivity was $1.4 \%$ ). Moreover, the tested VOM shows quiet good dynamic properties: the settling time was $66 \pm 5 \mathrm{~ms}$. This value is higher than other differential-producing flowmeters; for instance, studies show that Fleisch pneumotachograph and orifice meter have a response time slightly higher than $2 \mathrm{~ms}[16,19]$. Lastly, long lasting experiments show that the sensor's sensitivity did not change, and its precision shows a very low deterioration, despite the formation of vapour condensation.

Sensor under test presents many advantages for respiratory function monitoring: low dead space $(7 \mathrm{~mL})$, good sensitivity and low discrimination threshold $\left(<0.5 \mathrm{~L} \cdot \mathrm{min}^{-1}\right)$, quiet good step response, and good bidirectionality, and its performances are not significantly deteriorated by condensation.
Therefore, in comparison with other solutions, VOMs show some advantages: with respect to the fixed orifice meters, they have a linear response; they are more robust and cheaper than hot wire anemometers [29]; moreover they are not prone to sensitivity changes due to condensation, differently from Fleisch pneumotachographs which require ad hoc solutions to minimize this concern, such as the use of an electric resistance. These features make VOM reliable for measurements also in other medical applications. For instance, this kind of sensor may be employed in the field of noninvasive methods for cardiac output estimation [3] in application related to the monitoring of human intestinal gases [30] and in other industrial processes in particular when bidirectional air flow rate must be measured.

\section{Conflict of Interests}

The authors declare that there is no conflict of interests regarding the publication of this paper.

\section{Authors' Contribution}

Giuseppe Tardi and Carlo Massaroni equally contributed to this work. 


\section{References}

[1] J. H. T. Bates, M. J. Turner, C. J. Lanteri, B. Jonson, and P. D. Sly, "Measurement of flow and volume," in Infant Respiratory Function Testin, J. Stocks, P. D. Sly, R. S. Tepper, and W. J. Morgan, Eds., chapter 5, John Wiley \& Sons, New York, NY, USA, 3rd edition, 1996.

[2] K. Makita, J. F. Nunn, and B. Royston, "Evaluataion of metabolic measuring instruments for use in critically ill patients," Critical Care Medicine, vol. 18, no. 6, pp. 638-644, 1990.

[3] S. Cecchini, E. Schena, M. Notaro, M. Carassiti, and S. Silvestri, "Non-invasive estimation of cardiac output in mechanically ventilated patients: a prolonged expiration method," Annals of Biomedical Engineering, vol. 40, no. 8, pp. 1777-1789, 2012.

[4] P. J. Peyton, D. Thompson, and P. Junor, "Non-invasive automated measurement of cardiac output during stable cardiac surgery using a fully integrated differential $\mathrm{CO}_{2}$ Fick method," Journal of Clinical Monitoring and Computing, vol. 22, no. 7, pp. 285-292, 2008.

[5] H. Jewitt and G. Thomas, "Measurement of flow and volume of gases," Anaesthesia \& Intensive Care Medicine, vol. 13, no. 3, pp. 106-110, 2012.

[6] R. W. Miller, "Introduction to the differential producer," in Flow Measurement Engineering Handbook, R. W. Miller, Ed., chapter7, McGraw-Hill, New York, NY, USA, 3rd edition, 1996.

[7] E. Schena, C. Massaroni, P. Saccomandi, and S. Cecchini, "Flow measurement in mechanical ventilation: a review," Medical Engineering \& Physics, vol. 37, no. 3, pp. 257-264, 2015.

[8] A. Abou El-Azm Aly, A. Chong, F. Nicolleau, and S. Beck, "Experimental study of the pressure drop after fractal-shaped orifices in turbulent pipe flows," Experimental Thermal and Fluid Science, vol. 34, no. 1, pp. 104-111, 2010.

[9] G. L. Morrison, D. Terracina, C. Brewer, and K. R. Hall, "Response of a slotted orifice flow meter to an air/water mixture," Flow Measurement and Instrumentation, vol. 12, no. 3, pp. 175-180, 2001.

[10] J. J. Osborn, "Variable orifice gas flow sensing head," US Patent 4,083,245, 1978.

[11] D. W. Guillaume, M. G. Norton, and D. F. DeVries, "Variable orifice flow sensing apparatus," US Patent 4,993,269, February 1991.

[12] J. Stupecky, "Variable area obstruction gas flow meter," US patent 5,083,621, 1991.

[13] M. B. Jaffe, "Technical perspectives: gas flow measurement," in Capnography, J. S. Gravenstein, M. B. Jaffe, N. Gravenstein, and D. A. Palus, Eds., pp. 397-405, Cambridge University Press, NewYork, NY, USA, 2011.

[14] A. Fleisch, "Der Pneumotachograph; ein Apparat zur Geschwindigkeitsregistrierung der Atemluft," Pflüger's Archiv für die gesamte Physiologie des Menschen und der Tiere, vol. 209, no. 1, pp. 713-722, 1925.

[15] J. C. Lilly, "Flowmeter for recording respiratory flow of human subjects," Methods in Medical Research, vol. 2, pp. 113-121, 1950.

[16] E. Schena, G. Lupi, S. Cecchini, and S. Silvestri, "Linearity dependence on oxygen fraction and gas temperature of a novel Fleisch pneumotachograph for neonatal ventilation at low flow rates," Measurement, vol. 45, no. 8, pp. 2064-2071, 2012.

[17] Measurement of fluid flow by means of pressure differential devices inserted in circular cross-section conduits running full. Part2. Orifice plates, EN ISO 5167-2, 2003.
[18] Joint Committee for Guides in Metrology, "Evaluation of measurement data-guide to the expression of uncertainty in measurement," Tech. Rep. JCGM 100, JCGM, 2008.

[19] E. Schena, S. Cecchini, and S. Silvestri, "An orifice meter for bidirectional air flow measurements: influence of gas thermohygrometric content on static response and bidirectionality," Flow Measurement and Instrumentation, vol. 34, pp. 105-112, 2013.

[20] M. Giorgino, G. Morbidoni, E. Tamilia, F. Taffoni, D. Formica, and E. Schena, "Design and characterization of a bidirectional, low cost flowmeter for neonatal ventilation," IEEE Sensors Journal, vol. 14, no. 12, pp. 4354-4360, 2014.

[21] S. N. Ryan, N. Rankin, E. Meyer, and R. Williams, "Energy balance in the intubated human airway is an indicator of optimal gas conditioning," Critical Care Medicine, vol. 30, no. 2, pp. 355-361, 2002.

[22] E. Schena, P. Saccomandi, C. Ramandi, and S. Silvestri, "A novel control strategy to improve the performances of heated wire humidifiers in artificial neonatal ventilation," Physiological Measurement, vol. 33, no. 7, pp. 1199-1211, 2012.

[23] M. R. Miller and T. Sigsgaard, "Prevention of thermal and condensation errors in pneumotachographic recordings of the maximal forced expiratory manoeuvre," European Respiratory Journal, vol. 7, no. 1, pp. 198-201, 1994.

[24] D. R. Hess, "Approaches to conventional mechanical ventilation of the patient with acute respiratory distress syndrome," Respiratory Care, vol. 56, no. 10, pp. 1555-1572, 2011.

[25] M. Zimová-Herknerová and R. Plavka, "Expired tidal volumes measured by hot-wire anemometer during high-frequency oscillation in preterm infants," Pediatric Pulmonology, vol. 41, no. 5, pp. 428-433, 2006.

[26] P. Latzin, L. Sauteur, C. Thamrin et al., "Optimized temperature and deadspace correction improve analysis of multiple breath washout measurements by ultrasonic flowmeter in infants," Pediatric Pulmonology, vol. 42, no. 10, pp. 888-897, 2007.

[27] Y. Snepvangers, P. De Winter, H. Burger, H. A. Brouwers, J. M. Bogaard, and K. Van Der Ent, "Correction factors for oxygen and flow-rate effects on neonatal Fleisch and Lilly pneumotachometers," Pediatric Critical Care Medicine, vol. 4, no. 2, pp. 227-232, 2003.

[28] M. J. Heulitt, J. H. Shirley, and L. Thurman, "Accuracy of small tidal volume measurement comparing two ventilator airway sensors," Journal of Pediatric Intensive Care, vol. 2, no. 1, pp. 3338, 2013.

[29] H. H. Bruun, Hot Wire Anemometry in Principles and Signal Analysis, Oxford University Press, New York, NY, USA, 1996.

[30] J. Z. Ou, C. K. Yao, A. Rotbart, J. G. Muir, P. R. Gibson, and K. Kalantar-zadeh, "Human intestinal gas measurement systems: in vitro fermentation and gas capsules," Trends in Biotechnology, vol. 33, no. 4, pp. 208-213, 2015. 

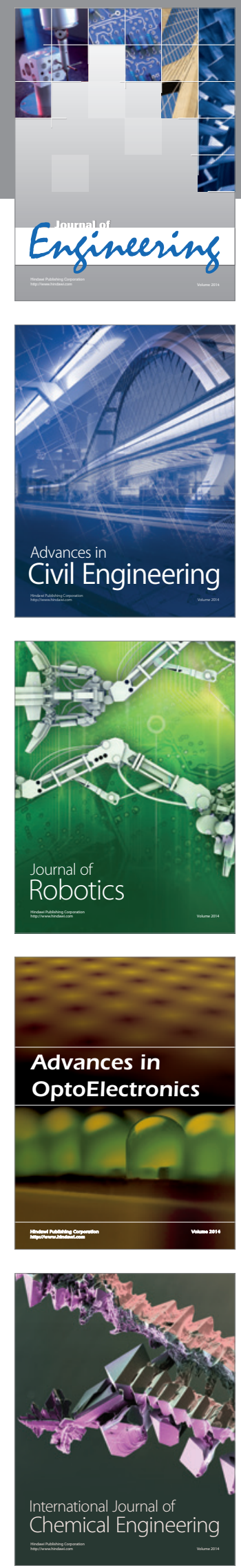

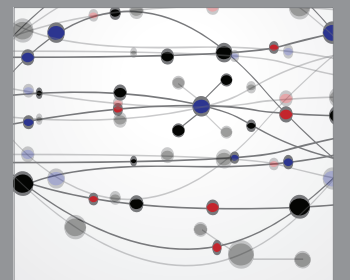

The Scientific World Journal
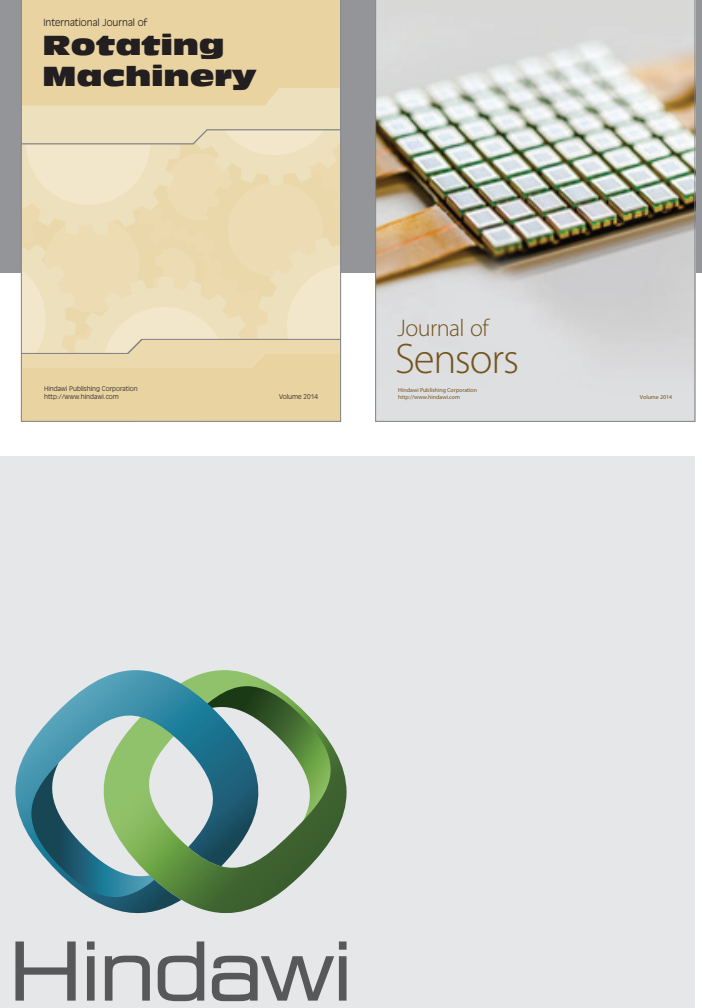

Submit your manuscripts at http://www.hindawi.com
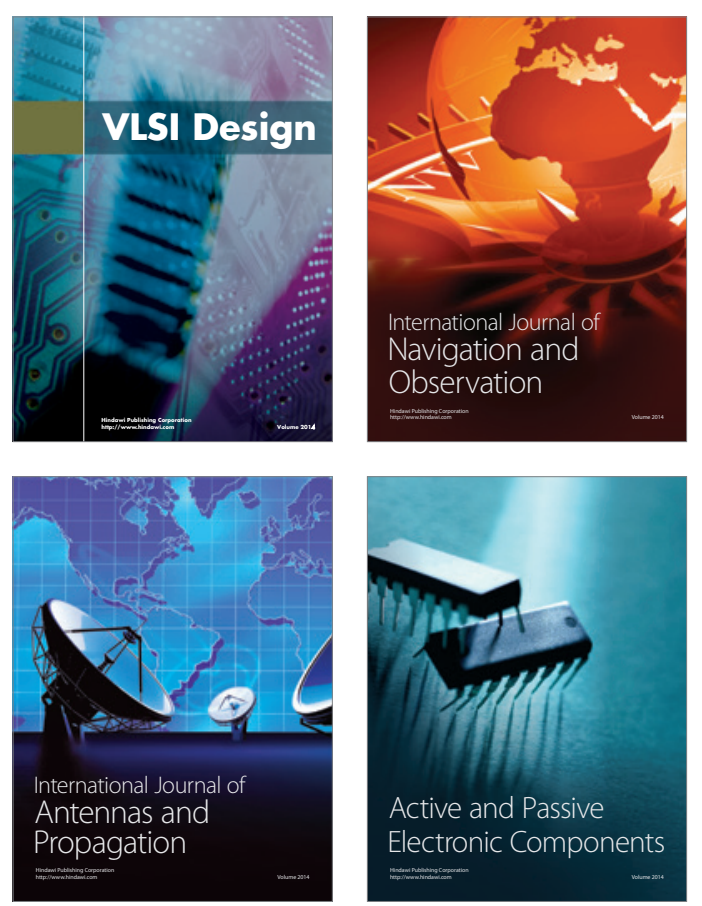
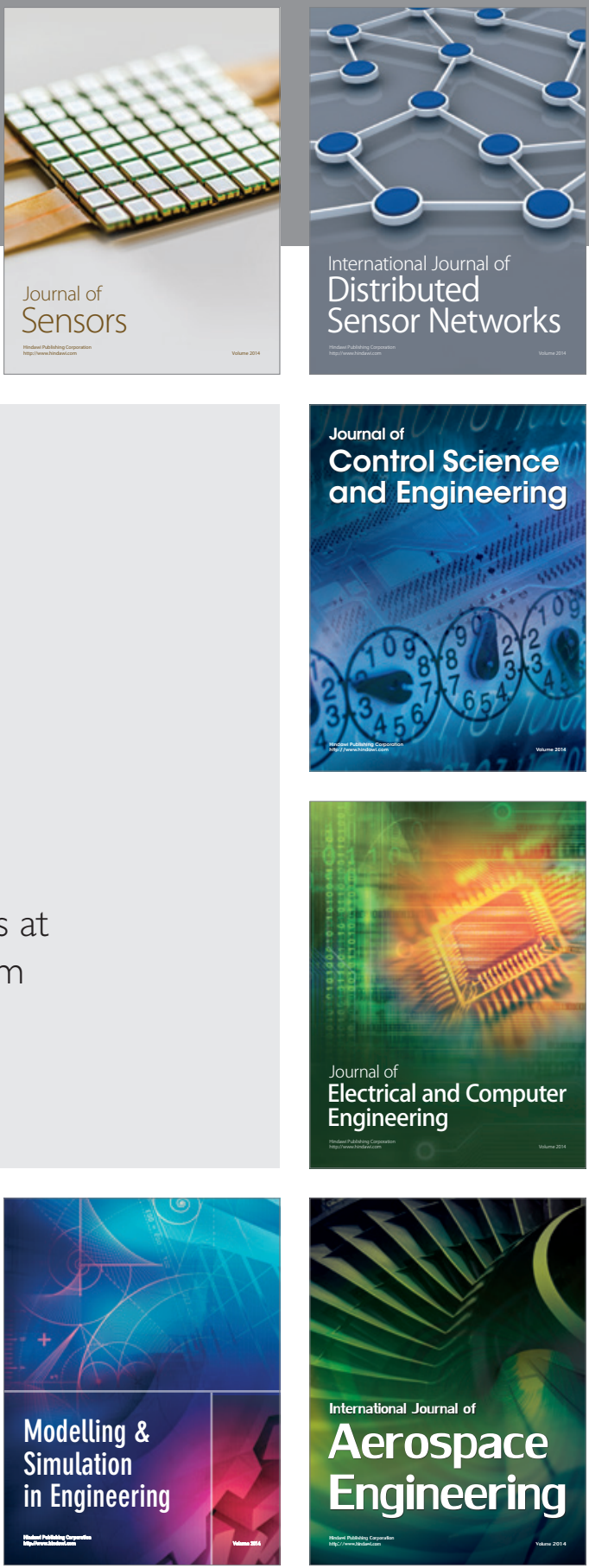

Journal of

Control Science

and Engineering
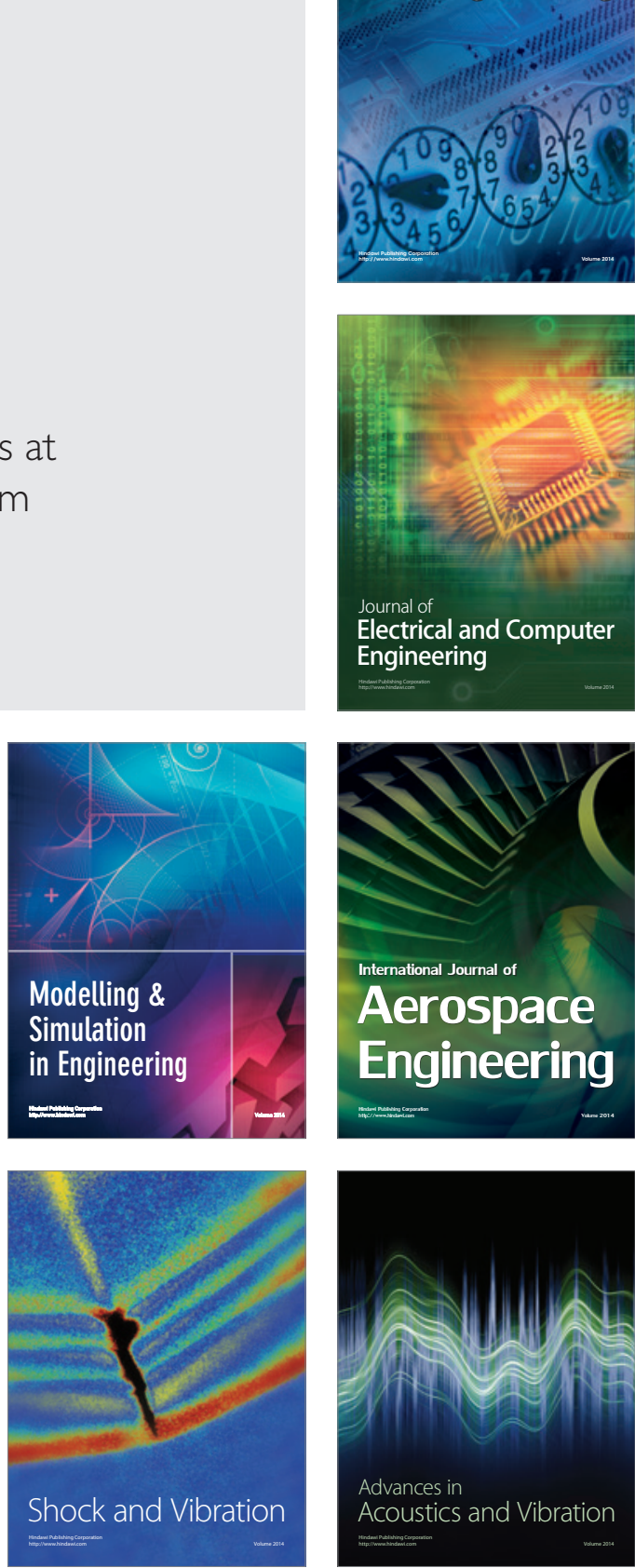